\title{
Fontes e manejos da adubação nitrogenada em algodoeiro ${ }^{1}$
}

\author{
Flávio Hiroshi Kaneko², Aguinaldo José Freitas Leal ${ }^{3}$, \\ Jefferson Luís Anselmo², Salatiér Buzetti², Fábio da Silva Tosta ${ }^{3}$
}

\begin{abstract}
Sources and managements

of nitrogen fertilization in cotton plants

The development of new technologies that aim at increasing the efficiency of nitrogen $(\mathrm{N})$ fertilizers is essential for the agricultural sustainability. Thus, this study aimed at evaluating the cotton plants response to different topdressing $\mathrm{N}$ sources, under no-till system, in the Brazilian Savannah, in the 2008/2009 and 2009/2010 growing seasons. Treatments consisted of three $\mathrm{N}$ sources (urea, urea with urease inhibitor and ammonium nitrate) and two topdressing $\mathrm{N}$ fertilization applications (one application at $\mathrm{V}_{5}$ and two applications, as it follows: $50 \%$ at $\mathrm{V}_{5}+50 \%$ at $\mathrm{B}_{6}$ ), plus a control (without topdressing $\mathrm{N}$ ). The ammonium nitrate application provided the best results for both seasons, while the urea with urease inhibitor differed from urea only in the first season. The topdressing $\mathrm{N}$ fertilization provided different results among crops, being dependent of environmental conditions. If there is sufficient rainfall to incorporate the $\mathrm{N}$ to soil, better yields can be expected, when all the topdressing fertilization takes place at the $\mathrm{V}_{5}$ stage.
\end{abstract}

KEY-WORDS: Gossypium hirsutum L.; urease inhibitor; topdressing fertilization.

\section{INTRODUÇÃO}

O cultivo do algodoeiro passou de uma atividade alternativa, para pequenos e médios produtores, a um sistema de produção em escala, com o uso de variedades com arquitetura favorável à colheita mecanizada, caracterizadas por altas produtividades e intenso uso de insumos, principalmente na região do Cerrado (Leal et al. 2009). Como os fertilizantes representam $28 \%$ do custo operacional total desta atividade (Leal et al. 2011), este item merece grande atenção do produtor e da pesquisa, principalmente os fertilizantes nitrogenados.

\section{RESUMO}

O desenvolvimento de tecnologias que visem a aumentar a eficiência dos fertilizantes nitrogenados é de fundamental importância para a sustentabilidade da agricultura. Assim, este trabalho objetivou avaliar a resposta do algodoeiro a diferentes fontes de nitrogênio $(\mathrm{N})$ em cobertura, aplicadas em sistema plantio direto, no Cerrado, nos anos agrícolas 2008/2009 e 2009/2010. Os tratamentos constituíram-se de três fontes de $\mathrm{N}$ (ureia, ureia com inibidor de urease e nitrato de amônio) e dois manejos da adubação de $\mathrm{N}$ em cobertura (uma aplicação em $\mathrm{V}_{5}$ e duas aplicações, como se segue: $50 \%$ em $\mathrm{V}_{5}+50 \%$ em $\mathrm{B}_{6}$ ), além de uma testemunha (sem $\mathrm{N}$ em cobertura). $\mathrm{O}$ nitrato de amônio promoveu melhor resultado, nos dois períodos avaliados, enquanto a ureia com inibidor de urease diferiu da ureia comum apenas no primeiro ano. $\mathrm{O}$ manejo do $\mathrm{N}$ em cobertura propiciou resultados diferentes entre os cultivos, sendo dependente das condições ambientais. Caso ocorra precipitação suficiente para incorporação do $\mathrm{N}$ ao solo, pode haver melhores produtividades, quando o adubo de cobertura for aplicado todo na fase $\mathrm{V}_{5}$.

PALAVRAS-CHAVES: Gossypium hirsutum L.; inibidor de urease; adubação de cobertura.

O nitrogênio é o nutriente mais requerido pelo algodoeiro, porém, sua recomendação tem sido feita, muitas vezes, de maneira empírica, não se levando em consideração a resposta da cultura e o solo (Rosolém \& Mellis 2010). Para maior redução de perdas e aproveitamento do fertilizante pela cultura, preconiza-se trabalhar com o seu fornecimento em aplicações parceladas. Neste sentido, Souza \& Lobatto (2004) recomendam que a adubação nitrogenada em cobertura, para o algodoeiro cultivado no Cerrado, seja feita em função da expectativa de produtividade, e que doses superiores a $40 \mathrm{~kg}$ de $\mathrm{N} \mathrm{ha}^{-1}$ devem ser parceladas em duas aplicações, aos 30 e 50 dias após a emergência.

1. Trabalho recebido em ago./2012 e aceito para publicação em mar./2013 (nº registro: PAT 19581).

2. Universidade Estadual Paulista (Unesp), Faculdade de Engenharia, Ilha Solteira, SP, Brasil. E-mails: fhkaneko@hotmail.com, jefferson@fundacaochapadao.com.br, sbuzetti@agr.feis.unesp.br.

3. Universidade Federal de Mato Grosso do Sul (UFMS), Chapadão do Sul, MS, Brasil.E-mails: aguinaldo.leal@ufms.br, fs_tosta@hotmail.com. 
Outro fator relevante se refere à fonte de nitrogênio adotada. De acordo com Cantarella \& Marcelino (2006), a ureia é o principal fertilizante sólido no mercado mundial. No Brasil, este produto responde por cerca de $60 \%$ dos fertilizantes nitrogenados comercializados, havendo clara preferência da indústria pela fabricação de ureia, em comparação com outras fontes sólidas de nitrogênio, em função do menor custo e maior facilidade de produção.

Com a finalidade de reduzir perdas de $\mathrm{N}$, principalmente por volatilização da amônia, várias modificações têm sido feitas em fertilizantes contendo ureia. Estas incluem a adição de produtos acidificantes e a produção de fertilizantes com solubilidade controlada, por meio de resinas ou polímeros, ou mesmo com a cobertura de enxofre elementar.

Existem vários produtos comerciais com solubilidade controlada comercializados no mundo, mas, devido ao elevado preço, são utilizados em nichos de mercado, por culturas de alto valor agregado (Cantarella \& Marcelino 2006). Recentemente, a elevação dos preços dos fertilizantes nitrogenados tem viabilizado a adoção de alguns destes produtos em culturas anuais. Dentre estes produtos comerciais, destacam-se os "fertilizantes estabilizados", que contêm aditivos para aumentar o tempo de disponibilidade no solo, tais como inibidores de nitrificação, inibidores de urease ou outros aditivos (Cantarella 2007). O mesmo autor relata que o produto aparentemente mais promissor é o NBPT (tiofosfato de $\mathrm{N}$-n-butiltriamida ou N-n-butiltriamida do ácido tiofosfórico), que funciona como inibidor de urease.

Trenkel (1997) ressalta que os inibidores de urease previnem ou diminuem, ao longo de certo período de tempo, a transformação do $\mathrm{N}$-amídico em amônia e a hidrólise enzimática (urease) da ureia no solo, reduzindo as perdas por volatilização e, também, as perdas adicionais por lixiviação do nitrato, aumentando a eficiência da ureia.

Leal et al. (2010), trabalhando com doses de $\mathrm{N}$ em cobertura, na cultura do algodoeiro, com as fontes ureia com NBPT e ureia convencional, observaram que a primeira fonte, na dose de $120 \mathrm{~kg} \mathrm{ha}^{-1}$ de $\mathrm{N}$ em cobertura, foi suficiente para proporcionar produtividade máxima de $4.650 \mathrm{~kg} \mathrm{ha}^{-1}$ de algodão em caroço, enquanto, com a ureia, na dose de $180 \mathrm{~kg}$ de $\mathrm{N} \mathrm{ha}^{-1} \mathrm{em}$ cobertura, obteve-se produtividade inferior (4.500 kg ha-1).

Da mesma forma, pesquisas relacionadas ao manejo do $\mathrm{N}$ vêm sendo feitas com outras culturas
(Kaneko et al. 2010a, Arf et al. 2011), com o intuito de garantir o máximo aproveitamento do $\mathrm{N}$, associado à lucratividade do empreendimento agrícola (Kaneko et al. 2010b) e facilidades nos aspectos operacionais, em relação à condução da cultura no campo (antecipação da aplicação e parcelamento da adubação em uma ou duas aplicações).

Muitos questionamentos são observados no campo, por parte de agricultores e técnicos, em relação à eficiência da ureia revestida com produtos (inibidores de urease e inibidores de nitrificação ou polímeros) disponíveis, atualmente, no mercado, frente às fontes tradicionais (ureia e nitrato de amônio). Além disto, indaga-se sobre a época de aplicação e a eficiência econômica, para se respeitar, o máximo possível, a marcha de absorção do nitrogênio pelas culturas, principalmente no cultivo do algodoeiro, no qual divide-se a adubação nitrogenada em três épocas (semeadura e duas aplicações em cobertura). Assim, este estudo objetivou avaliar a resposta do algodoeiro a diferentes fontes de $\mathrm{N}$, em dois manejos da adubação de cobertura, em sistema plantio direto, no Cerrado.

\section{MATERIAL E MÉTODOS}

Foram conduzidos dois experimentos, durante os anos agrícolas 2008/2009 e 2009/2010, na área experimental da Fundação de Apoio à Pesquisa Agropecuária de Chapadão (Fundação Chapadão), localizada no município de Chapadão do Sul, MS (18 $41^{\circ} 33^{\prime \prime} \mathrm{S}, 52^{\circ} 40^{\prime} 45^{\prime \prime} \mathrm{W}$ e $810 \mathrm{~m}$ de altitude), em duas áreas com Latossolo Vermelho distrófico, de textura argilosa, cujas características químicas são apresentadas na Tabela 1.

Em ambos os anos agrícolas, o cultivo foi realizado sob sistema plantio direto estabelecido, tendo como cultura anterior a soja, cultivada em safra no "verão", e o sorgo granífero, na segunda safra ou "safrinha". A precipitação média regional é de $1.500 \mathrm{~mm}$, a temperatura média de $21^{\circ} \mathrm{C}$ e a umidade relativa média anual de 50\% a 70\% (Tomquelski 2009). Os dados de precipitação encontram-se ilustrados na Figura 1.

A semeadura do algodoeiro foi realizada em 13/12/2008 e 15/12/2009, com as cultivares BRS Buriti e FMX 993, respectivamente, sendo que a adubação constituiu-se de $100 \mathrm{~kg} \mathrm{ha}^{-1}$ de $\mathrm{KCl}$, em pré-semeadura a lanço, e $420 \mathrm{~kg} \mathrm{ha}^{-1}$ da fórmula 05-23-15, no sulco de semeadura, em ambos os anos agrícolas. 
Tabela 1. Características químicas do solo das áreas utilizadas nos respectivos anos agrícolas de condução dos experimentos (Chapadão do Sul, MS, safras 2008/2009 e 2009/2010).

\begin{tabular}{|c|c|c|c|c|c|c|c|c|}
\hline \multirow{2}{*}{ Ano } & M.O. & \multirow{2}{*}{$\mathrm{pH}$} & $\mathrm{P}$ & $\mathrm{S}$ & $\mathrm{K}$ & $\mathrm{Ca}$ & $\mathrm{Mg}$ & $\mathrm{H}+\mathrm{Al}$ \\
\hline & $\mathrm{g} \mathrm{dm}^{-3}$ & & \multicolumn{2}{|c|}{$\mathrm{mg} \mathrm{dm}^{-3}$} & \multicolumn{4}{|c|}{$\mathrm{mmol}_{\mathrm{c}} \mathrm{dm}^{-3}$} \\
\hline $2008 / 2009$ & 47 & 5,0 & 57 & 5 & 2,5 & 57 & 11 & 44 \\
\hline $2009 / 2010$ & 31 & 4,7 & 39 & 23 & 2,3 & 34 & 11 & 48 \\
\hline
\end{tabular}

O manejo de pragas, doenças, plantas daninhas e regulador de crescimento foram realizados de acordo com as recomendações locais da Fundação Chapadão e a colheita foi realizada manualmente, em 14/07/2009 e 11/07/2010.

Os tratamentos constituíram-se de três fontes de $\mathrm{N}$ (ureia, ureia com inibidor de urease e nitrato de amônio) e dois manejos da adubação de $\mathrm{N}$ em cobertura (uma aplicação em $\mathrm{V}_{5}$ e duas aplicações, como se segue: $50 \%$ em $\mathrm{V}_{5}+50 \%$ em $\mathrm{B}_{6}$ ), além de uma testemunha (sem $\mathrm{N}$ em cobertura), formando um fatorial incompleto $(3 \times 2+1)$, com cinco repetições, conduzido em blocos casualizados. Todos os fertilizantes utilizados são comerciais. As parcelas foram formadas por quatro linhas de 10,0 m de comprimento, sendo consideradas, como área útil, as duas linhas centrais, com 4,0 m.

As adubações de cobertura, conforme os tratamentos, foram efetuadas manualmente, em faixas de $0,2 \mathrm{~m}$ ao lado da linha da cultura, utilizando-se a dose de $100 \mathrm{~kg} \mathrm{ha}^{-1}$ de $\mathrm{N}$, nas fases $\mathrm{V}_{5}$ e $\mathrm{B}_{6}$, nos dias 19/01/2009 e 03/02/2009, para o ano agrícola 2008/2009, e em 15/01/2010 e 02/02/2010, para o ano agrícola 2009/2010, respectivamente (Figura 1).

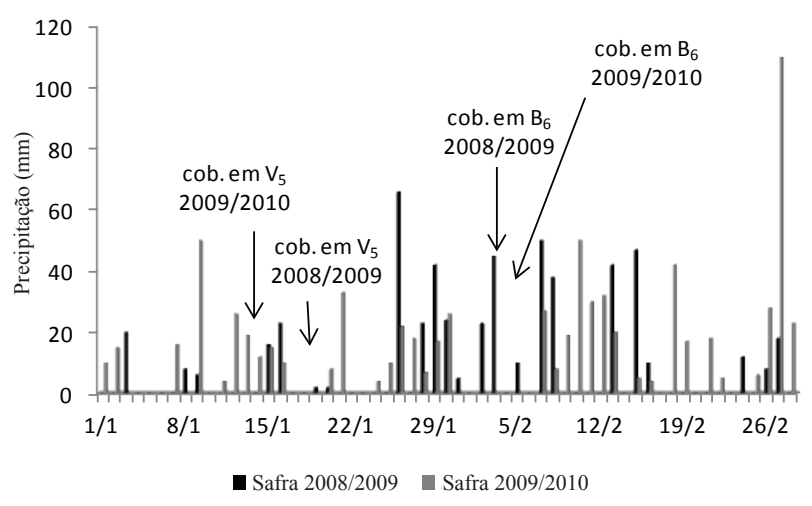

Figura 1. Precipitação diária dos meses de janeiro e fevereiro e datas das adubações nitrogenadas em cobertura nas fases $\mathrm{V}_{5}$ (janeiro) e $\mathrm{B}_{6}$ (fevereiro) (Chapadão do Sul, MS, safras 2008/2009 e 2009/2010).
As seguintes características foram avaliadas: a) população de plantas: na colheita, foram contadas as plantas na área útil da parcela experimental; b) altura de plantas: altura até o último nó do ápice (média de três plantas por parcela); c) massa de 10 capulhos: coletou-se, aleatoriamente, 10 capulhos do terço médio das plantas da área experimental; d) produtividade de algodão em caroço: após a abertura de $80 \%$ dos capulhos, foi realizada a colheita manual dos mesmos, sendo a produtividade expressa em massa de algodão em caroço.

Os dados obtidos foram submetidos à análise de variância, utilizando-se o programa Sisvar, e as comparações entre as médias foram feitas pelo teste de Scott-Knott, a 5\%. O efeito do nitrogênio foi avaliado por meio de contraste ortogonal $(\mathrm{C} 1=$ média do tratamento testemunha - média do fatorial fonte $\mathrm{x}$ manejo do $\mathrm{N}$ ).

\section{RESULTADOS E DISCUSSÃO}

Verificou-se que houve efeito significativo $(\mathrm{p}<0,01)$ da adubação nitrogenada em cobertura sobre a altura de plantas (2009/2010) e produtividade de algodão em caroço (2008/2009 e 2009/2010), efeito não observado para a população de plantas e massa de 10 capulhos, tanto no ano agrícola 2008/2009 quanto no ano 2009/2010 (Tabela 2).

Não houve interação significativa $(p>0,05)$ entre fontes e manejos do nitrogênio em cobertura para nenhuma variável analisada (Tabela 3). A população final de plantas encontra-se próxima aos valores sugeridos por Lamas (2006), que recomenda, para condições similares às deste trabalho, população inicial variando entre 80.000 plantas ha $^{-1}$ e 125.000 plantas ha $^{-1}$, devendo ser mantido o limite inferior deste intervalo, quando as condições de clima, solo e variedades forem favoráveis a altas produtividades.

No primeiro ano de cultivo (2008/2009), não houve efeito significativo $(p>0,05)$ da adubação nitrogenada (Tabela 2) para a altura de plantas, 
Tabela 2. Valores de F para o contraste ortogonal referente ao efeito do nitrogênio sobre a população de plantas, altura de plantas, massa de 10 capulhos e produtividade do algodão em caroço (Chapadão do Sul, MS, safras 2008/2009 e 2009/2010).

\begin{tabular}{lrr}
\hline \multirow{2}{*}{ Variável analisada } & \multicolumn{2}{c}{$\mathrm{F}(\text { contraste })^{1}$} \\
\cline { 2 - 3 } & \multicolumn{1}{c}{$2008 / 2009$} & \multicolumn{1}{c}{$2009 / 2010$} \\
\hline População de plantas & $0,04(\mathrm{p}>0,05)$ & $0,47(\mathrm{p}>0,05)$ \\
Altura de plantas & $0,26(\mathrm{p}>0,05)$ & $15,38(\mathrm{p}<0,01)$ \\
Massa de 10 capulhos & $0,01(\mathrm{p}>0,05)$ & $0,06(\mathrm{p}>0,05)$ \\
Produtividade & $47,59(\mathrm{p}<0,01)$ & $7,81(\mathrm{p}<0,01)$ \\
\hline
\end{tabular}

${ }^{1}$ Média do tratamento testemunha - média do fatorial fonte $\mathrm{x}$ manejo do $\mathrm{N}$.

porém, no ano agrícola seguinte, houve resposta do algodoeiro à adubação nitrogenada para esta variável (Tabela 2). O uso da ureia com NBPT e nitrato de amônio proporcionaram maior altura de plantas que a ureia tradicional (Tabela 3 ). Em relação ao manejo da adubação de cobertura, quando aplicou-se $100 \%$, na fase $\mathrm{V}_{5}$, verificou-se valor significativamente superior ao obtido com o manejo com $50 \%$ na fase $\mathrm{V}_{5}+50 \%$ na fase $\mathrm{B}_{6}$. Isto ocorreu em função da incorporação do $\mathrm{N}$ pela precipitação natural ocorrida na fase $\mathrm{V}_{5}$, além da menor precipitação logo após a segunda cobertura, na fase $\mathrm{B}_{6}$ (Figura 1 ).

A massa de 10 capulhos não foi influenciada $(p>0,05)$ pela adubação nitrogenada (Tabela 2), nos dois anos de cultivo avaliados. No primeiro cultivo, os valores foram $9,7 \%$ maiores que no segundo (Tabela 4), o que pode estar relacionado às diferenças genéticas entre as cultivares utilizadas. Lamas (2001) cita que a massa dos capulhos é influenciada diretamente pelo equilíbrio entre as partes vegetativas e reprodutivas da planta, indicando, desta forma, que a adubação nitrogenada não alterou este equilíbrio, para as condições em questão, indo ao encontro dos resultados obtidos por Furlani Júnior et al. (2003), que, comparando o efeito da adubação nitrogenada associada ao regulador vegetal e densidade de plantas, para o Estado de São Paulo, não verificaram resposta significativa do nitrogênio sobre a massa de capulhos do algodoeiro.

Em relação à produtividade de algodão em caroço, houve efeito significativo $(p<0,05)$ da adubação nitrogenada, em ambos os cultivos (Tabela 2). Verificou-se que as fontes de $\mathrm{N}$ influenciaram significativamente na produtividade do algodão em caroço, para ambos os anos agrícolas, com destaque para o nitrato de amônio, pois proporcionou as maiores médias, em relação à ureia tradicional e ureia com NBPT (Tabela 4). No ano agrícola 2008/2009, o uso de ureia com NBPT resultou em maior produtividade, em relação à ureia tradicional, de maneira similar ao resultado obtido por Leal et al. (2010), em condições semelhantes de cultivo.

Por outro lado, Valderrama et al. (2009), ao avaliarem o efeito de fontes de $\mathrm{N}$ (ureia e ureia revestida com polímero), não constataram resposta do feijoeiro "de inverno" em solos de Cerrado de baixa altitude. Valderrama et al. (2011) também não

Tabela 3. População de plantas e altura do algodoeiro, em função de fontes e formas de aplicação de nitrogênio (Chapadão do Sul, MS, safras 2008/2009 e 2009/2010).

\begin{tabular}{|c|c|c|c|c|}
\hline \multirow{2}{*}{ Fonte de variação } & \multicolumn{2}{|c|}{ População de plantas (plantas ha-1) } & \multicolumn{2}{|c|}{ Altura de plantas $(\mathrm{m})$} \\
\hline & $2008 / 2009$ & $2009 / 2010$ & $2008 / 2009$ & $2009 / 2010$ \\
\hline \multicolumn{5}{|l|}{ Fontes de $N$} \\
\hline Ureia & 86.718 & 77.604 & 1,10 & $0,92 \mathrm{~b}$ \\
\hline Ureia com NBPT & 85.967 & 76.042 & 1,07 & $0,99 \mathrm{a}$ \\
\hline Nitrato de amônio & 79.688 & 81.076 & 1,12 & $1,00 \mathrm{a}$ \\
\hline \multicolumn{5}{|l|}{ Manejo do $N$} \\
\hline $100 \% \mathrm{em} \mathrm{V}_{5}$ & 83.281 & 77.517 & 1,09 & $1,04 \mathrm{a}$ \\
\hline $50 \%$ em $\mathrm{V}_{5}+50 \% \mathrm{em} \mathrm{B}_{6}$ & 84.843 & 77.519 & 1,08 & $0,93 \mathrm{~b}$ \\
\hline Testemunha & 83.438 & 75.347 & 1,06 & 0,85 \\
\hline \multicolumn{5}{|l|}{ Teste $F$} \\
\hline Fontes $(\mathrm{F})$ & 1,27 & 0,52 & 1,65 & $5,52(\mathrm{p}<0,05)$ \\
\hline Manejo (M) & 0,56 & 0,01 & 0,19 & $24,89(\mathrm{p}<0,01)$ \\
\hline $\mathrm{F} \times \mathrm{M}$ & 1,74 & 1,06 & 0,55 & 0,29 \\
\hline C.V. (\%) & 7,51 & 12,97 & 7,25 & 6,14 \\
\hline
\end{tabular}

Médias seguidas de mesma letra não diferem entre si, a 5\%, pelo teste de Scott-Knott. 
Tabela 4. Massa de 10 capulhos e produtividade do algodão em caroço, em função de fontes e formas de aplicação de nitrogênio (Chapadão do Sul, MS, safras 2008/2009 e 2009/2010).

\begin{tabular}{lcccc}
\hline \multirow{2}{*}{ Fonte de variação } & \multicolumn{2}{c}{ Massa de 10 capulhos $(\mathrm{g})$} & \multicolumn{2}{c}{ Produtividade $\left(\mathrm{kg} \mathrm{ha}^{-1}\right)$} \\
\cline { 2 - 5 } & $2008 / 2009$ & $2009 / 2010$ & $2008 / 2009$ & $2009 / 2010$ \\
\hline Fontes de $N$ & 58,0 & & & \\
Ureia & 59,8 & 53,1 & $4.126 \mathrm{c}$ & $4.140 \mathrm{~b}$ \\
Ureia com NBPT & 59,5 & 53,7 & $4.304 \mathrm{~b}$ & $4.110 \mathrm{~b}$ \\
Nitrato de amônio & & 53,8 & $4.445 \mathrm{a}$ & $4.530 \mathrm{a}$ \\
\hline Manejo do $N$ & 60,0 & & & \\
$100 \%$ em V & 53,1 & $4.281 \mathrm{~b}$ & $4.575 \mathrm{a}$ \\
$50 \%$ em V F $_{5}+50 \%$ em B $_{6}$ & 60,5 & 54,7 & $4.416 \mathrm{a}$ & $4.125 \mathrm{~b}$ \\
Testemunha & 59,0 & 53,8 & 3.661 & 3.765 \\
\hline Teste F & & & & \\
Fontes (F) & 1,15 & 0,35 & $6,36(\mathrm{p}<0,01)$ & $3,51(\mathrm{p}<0,05)$ \\
Manejo (M) & 0,13 & 1,38 & $3,98(\mathrm{p}<0,05)$ & $9,31(\mathrm{p}<0,01)$ \\
F x M & 1,14 & 1,39 & 0,71 & 0,22 \\
\hline C.V. (\%) & 7,36 & 6,98 & 8,01 & 9,54 \\
\hline
\end{tabular}

Médias seguidas de mesma letra não diferem entre si, a 5\%, pelo teste de Scott-Knott.

verificaram diferenças entre fontes de $\mathrm{N}$ em cobertura, na produtividade da cultura do milho. Contudo, ambos os trabalhos foram conduzidos sob irrigação e, logo após a adubação nitrogenada de cobertura, foi realizada a aplicação de lâmina de água, visando a diminuir as perdas de $\mathrm{N}$ por volatilização.

É provável que, nas condições de realização do presente trabalho, o nitrato de amônio (2008/2009 e 2009/2010) e ureia com NBPT (2008/2009) tenham resultado em menores perdas por volatilização da amônia, quando comparados à ureia. Em condição edafoclimática semelhante, Pereira et al. (2009) verificaram menor volatilização da amônia nas parcelas que receberam ureia revestida com inibidor de urease, em comparação com a ureia tradicional.

Em relação ao manejo do nitrogênio, houve efeito significativo dos tratamentos $(p<0,05)$, em relação à produtividade do algodão em caroço (Tabela 4). No primeiro cultivo (2008/2009), o manejo do $\mathrm{N}$ com $50 \%$ em $\mathrm{V}_{5}+50 \%$ em $\mathrm{B}_{6}$ proporcionou $135 \mathrm{~kg} \mathrm{ha}^{-1}$ a mais de algodão em caroço, quando comparado ao manejo com $100 \% \mathrm{em} \mathrm{V}_{5}$. No entanto, no segundo ano (2009/2010), o efeito foi contrário, uma vez que a produtividade do algodão em caroço foi $9,8 \%$ maior, quando o manejo foi realizado com $100 \% \mathrm{em} \mathrm{V}_{5}$, se confrontado com o manejo com $50 \%$ em $\mathrm{V}_{5}+50 \%$ em B $_{6}$.

Considerando-se as condições meteorológicas ocorridas nos dois anos de estudo, no ano agrícola $2008 / 2009$, após a adubação nitrogenada em $V_{5}$ (19/01/2009), houve um "veranico" de sete dias, com precipitação de apenas $2,0 \mathrm{~mm}$, nos dias 19 e 20/01/2009 (Figura 1), o que acelerou o processo de volatilização da amônia para as fontes com ureia e impediu a liberação e o aproveitamento do $\mathrm{N}$ oriundo do nitrato de amônio, tornando importante a complementação com nitrogênio na fase $\mathrm{B}_{6}$, a qual, associada à precipitação de $45,0 \mathrm{~mm}$, no dia 03/02/2009 (Figura 1), explica a maior produtividade obtida no cultivo $2008 / 2009$, pelo manejo com $50 \%$ em $\mathrm{V}_{5}+50 \% \mathrm{em} \mathrm{B}_{6}$.

Em 2009/2010, a adubação nitrogenada realizada na fase $V_{5}(15 / 01 / 2010)$ também coincidiu com 15,0 mm de precipitação, ocorrida nesta mesma data, e mais 10,0 mm no dia seguinte (Figura 1). Estas precipitações, teoricamente, diminuiriam os problemas com volatilização da amônia das fontes contendo ureia. Contudo, é provável que não tenham sido suficientes para incorporar ao solo todo o $\mathrm{N}$ proveniente da fonte ureia, haja vista a menor altura de plantas proporcionada por esta, em relação às demais (Tabela 3). Este, por sua vez, pode ter ficado retido sobre a camada de resíduos vegetais com menor contato com o solo, o que potencializou as perdas de $\mathrm{N}_{-} \mathrm{NH}_{3}$ por volatilização, hipótese corroborada pelos resultados observados por Rojas et al. (2012).

Em contrapartida, a adubação de cobertura efetuada em $B_{6}$, no segundo cultivo (02/02/2010), não recebeu incorporação imediata do $\mathrm{N}$ aplicado por precipitação (Figura 1), tornando o nitrogênio das fontes com ureia mais propício a perdas por volatilização. Associado a isto, é possível que o "veranico" 
ocorrido entre os dias 31/01/2010 e 07/02/2010 não tenha permitido a disponibilização do $\mathrm{N}$ oriundo da fonte nitrato de amônio, para o algodoeiro.

Portanto, no manejo da adubação nitrogenada do algodoeiro, deve ser dada especial atenção à probabilidade de ocorrência de precipitações, após a aplicação em cobertura, sendo, este fator, determinante para o sucesso da adubação. Neste sentido, Lara Cabezas et al. (1997) afirmam que o umedecimento do solo, imediatamente após a aplicação de ureia, é mais importante para diminuir as perdas por volatilização do que a umidade do solo no momento da aplicação. Fontoura \& Bayer (2010), estudando a volatilização de $\mathrm{NH}_{3}$, em quatro safras agrícolas, observaram decréscimo exponencial nas perdas cumulativas de $\mathrm{N}$ ( $\%$ do total aplicado) com o aumento do volume de chuvas, no período de até cinco dias após a aplicação de $\mathrm{N}$.

A partir desses dados, é possível assumir que o produtor pode optar por fazer a adubação nitrogenada em cobertura toda na fase $\mathrm{V}_{5}$, para o algodoeiro, desde que as condições ambientais, principalmente de precipitação, sejam favoráveis ao aproveitamento do $\mathrm{N}$ pelas plantas, independentemente da fonte de $\mathrm{N}$ utilizada. Entretanto, havendo previsão de baixas precipitações, em período posterior à cobertura, a aplicação pode ser realizada de maneira parcelada, ou pode-se utilizar fonte que não apresente perdas por volatilização (nitrato) ou com potencial para reduzir a propensão a estas perdas (ureia com NBPT).

Kaneko et al. (2010b), analisando, economicamente, o efeito do manejo do nitrogênio em diferentes manejos do solo, associado ao arranjo de plantas, na cultura do milho, em região de Cerrado sob irrigação, observaram que, em sistema plantio direto, o parcelamento da adubação nitrogenada (ureia) de cobertura em duas aplicações $\left(50 \% \mathrm{em} \mathrm{V}_{4}+50 \%\right.$ em $\mathrm{V}_{8}$ ) resultou em maior índice de lucratividade somente em um dos anos de cultivo. Isto demonstra a dependência da resposta do nitrogênio às condições climáticas, mesmo em ambiente irrigado.

\section{CONCLUSÕES}

1. A fonte nitrato de amônio proporcionou as maiores produtividades de algodão em caroço, podendo a ureia revestida com NBPT ser mais eficiente que a ureia tradicional, em condições ambientais adversas, principalmente relacionadas com a baixa precipitação logo após a cobertura.
2. O manejo de $\mathrm{N}$ em cobertura, no algodoeiro, apresentou resultados diferenciados, sendo dependente das condições ambientais do local, após a aplicação, podendo haver melhores produtividades com a aplicação de $100 \%$ do $\mathrm{N}$ em $\mathrm{V}_{5}$, caso haja precipitação suficiente para a sua incorporação.

\section{AGRADECIMENTOS}

\begin{abstract}
À Fundação de Apoio à Pesquisa Agropecuária de Chapadão (Fundação Chapadão), pelo apoio à realização deste trabalho.
\end{abstract}

\section{REFERÊNCIAS}

ARF, M. V. et al. Fontes e épocas de aplicação de nitrogênio em feijoeiro de inverno sob sistema plantio direto. Pesquisa Agropecuária Tropical, Goiânia, v. 41, n. 3, p. 430-438, 2011.

CANTARELLA, H. Nitrogênio. In: NOVAIS, R. F. et al. Fertilidade do solo. Viçosa: SBCS, 2007. p. 375-471.

CANTARELLA, H.; MARCELINO, R. O uso do inibidor de urease para aumentar a eficiência da ureia. In: SIMPÓSIO SOBRE INFORMAÇÕES RECENTES PARA OTIMIZAÇÃO DA PRODUÇÃO AGRÍCOLA, 1., Piracicaba, 2006. Anais... Piracicaba: IPNI, 2006. Disponível em: $<$ http://www.ipni.net/ppiweb/pbrazil.nsf /\$webcontentsbydate?OpenView \&Start $=1 \&$ Count $=60 \&$ Expand=19\#19>. Acesso em: 20 nov. 2010.

FONTOURA, S. M. V.; BAYER, C. Ammonia volatilization in no-till system in the South-Central region of the State of Paraná. Revista Brasileira de Ciência do Solo, Viçosa, v. 34, n. 5, p. 1677-1684, 2010.

FURLANI JÚNIOR, E. et al. Modos de aplicação de regulador vegetal no algodoeiro, cultivar IAC-22, em diferentes densidades populacionais e níveis de nitrogênio em cobertura. Bragantia, Campinas, v. 62, n. 2, p. 227233, 2003.

KANEKO, F. H. et al. Manejo do solo e do nitrogênio em milho cultivado em espaçamento reduzido e tradicional. Bragantia, Campinas, v. 69, n. 3, p. 677-686, 2010a.

KANEKO, F. H. et al. Custo e rentabilidade do milho em função do manejo do solo e da adubação nitrogenada. Pesquisa Agropecuária Tropical, Goiânia, v. 40, n. 1, p. 102-109, 2010b.

LAMAS, F. M. Estudo comparativo entre cloreto de mepiquat e cloreto de chlormequat aplicados no algodoeiro. Pesquisa Agropecuária Brasileira, Brasília, DF, v. 36, n. 21, p. 227-233, 2001. 
LAMAS, F. M. Semeadura, espaçamento e densidade. In: MORESCO, E. Algodão: pesquisa e resultados para o campo. Cuiabá: Facual, 2006. p. 82-93.

LARA CABEZAS, W. A. R.; KORNDORFER, G. H.; MOTTA, S. A. Volatilização de $\mathrm{N}_{-} \mathrm{NH}_{3}$ na cultura de milho: I. Efeito da irrigação e substituição parcial da ureia por sulfato de amônio. Revista Brasileira de Ciência do Solo, Viçosa, v. 21, n. 3, p. 481-487, 1997.

LEAL, A. J. F. et al. Estimativa do custo de produção de algodão em caroço na região dos "Chapadões" safra 2011/12. Pesquisa - Tecnologia - Produtividade, Chapadão do Sul, v. 6, n. 1, p. 99-102, 2011.

LEAL, A. J. F. et al. Fontes e doses de nitrogênio na cultura do algodoeiro. In: REUNIÃO BRASILEIRA DE FERTILIDADE DO SOLO E NUTRIÇÃO DE PLANTAS, 29., 2010, Guarapari. Anais... Guarapari: SBCS/FertBio, 2010. 1 CD-ROM.

LEAL,A. J. F. et al. Comportamento de algodoeiro cultivado em região de Cerrado com diferentes espaçamentos e densidades de plantas. In: CONGRESSO BRASILEIRO DE ALGODÃO, 7., 2009, Foz do Iguaçu. Anais... Campina Grande: Embrapa Algodão, 2009. 1 CD-ROM.

PEREIRA, H. S. et al. Ammonia volatilization of urea in the out-of-season corn. Revista Brasileira de Ciência do Solo, Viçosa, v. 33, n. 6, p. 1685-1694, 2009.

ROJAS, C. A. L. et al. Volatilização de amônia da ureia alterada por sistemas de preparo de solo e plantas de cobertura invernais no centro-sul do Paraná. Revista Brasileira de Ciência do Solo, Viçosa, v. 36, n. 1, p. 261270, 2012.
ROSOLÉM, C. A.; MELLIS, V. V. Monitoring nitrogen nutrition in cotton. Revista Brasileira de Ciência do Solo, Viçosa, v. 34, n. 5, p. 1601-1607, 2010.

SOUZA, D. M. G.; LOBATO, E. Cerrado: correção do solo e adubação. Brasília, DF: Embrapa Informação Tecnológica, 2004.

TOMQUELSKI, G. V. Ocorrência de pragas e custo de produção em algodoeiro geneticamente modificado (Bt) e convencional. 2009. $108 \mathrm{f}$. Tese (Doutorado em Agronomia) - Universidade Estadual Paulista (Unesp), Ilha Solteira, 2009.

TRENKEL, M. E. Improving fertilizer use efficiency: controlled-release and stabilized fertilizers in agriculture. Paris: IFIA, 1997.

VALDERRAMA, M. et al. Fontes e doses de nitrogênio e fósforo em feijoeiro no sistema plantio direto. Pesquisa Agropecuária Tropical, Goiânia, v. 39, n. 3, p. 191-196, 2009.

VALDERRAMA, M. et al. Fontes e doses de NPK em milho irrigado sob plantio direto. Pesquisa Agropecuária Tropical, Goiânia, v. 41, n. 2, p. 254-263, 2011. 